\title{
Marija Jović
}

E-mail: jovic@pfri.hr

University of Rijeka, Faculty of Maritime Studies, Studentska 2, 51000 Rijeka, Croatia Jana Felicitas Schlierf

E-mail: jana.schlierf@student.jade-hs.de

Jade Hochschule Wilhelmshaven/Oldenburg/ Elsfleth, Fachbereich Seefahrt und Logistik, Weserstr. 52, 26931 Elsfleth, Germany

\section{Birte Heinen}

E-mail: birte.heinen@student.jade-hs.de

Jade Hochschule Wilhelmshaven/Oldenburg/ Elsfleth, Fachbereich Seefahrt und Logistik, Weserstr. 52, 26931 Elsfleth, Germany

\section{Edvard Tijan}

E-mail: etijan@pfri.hr

University of Rijeka, Faculty of Maritime Studies, Studentska 2, 51000 Rijeka, Croatia

\section{Information management in Reverse logistics}

\begin{abstract}
This paper presents an overview of challenges related to information management in reverse logistics and an overview of selected disruptive technologies (Internet of Things, Blockchain, Cloud computing and Artificial intelligence) that improve information management and information flow in the reverse logistics chain. The theoretical background of reverse logistics and selected disruptive technologies is provided. The goal of this paper is to research how information management in reverse logistics can be improved through the use of disruptive technologies. The research problem results from increased costs and insufficient prediction accuracy in the reverse logistics chain.
\end{abstract}

Keywords: Reverse logistics, Disruptive technologies, Information management

\section{Introduction}

Reverse logistics is an increasingly discussed subject both under the supply chain management literature and the environmental theme [44]. According to Rehman, Zhang \& Khan, [29], the concept of reverse logistics has gained immense popularity in the recent times and it basically means the reutilization of products and materials. Reverse logistics is considered to be one of the most complicated and costly process in e-commerce logistics according both to literature and industry interview outcomes [46]. 
Reverse logistics is a part of the total logistics of a company and deals with the handling of the goods that are being returned to the manufacturer by the customer, covering all the activities that determine the fate of these returned goods [28]. In addition to the forward flow of products, most firms have reverse flows of products that are either returned by customers or actively taken back by the firm itself, often for the purpose of reuse or resale [23].

The reverse logistics process consists of a series of activities required to collect an obsolete, unused, or disposal product, in order to generate revenue through recycling or resale in the secondary market, but also to guarantee environmentally correct disposal [44].

According to Nicolau, J. J. N. [27], "reverse logistics provide two major sources of benefits: environmental and economic benefits. In terms of the environment, supply chain with reverse logistics can collect and use the returns from the end-user market. This action reduces the amount of materials deposit to landfill or incinerators which in turn protects our ecosystem. In terms of economics benefits, the returns are assumed to cost less than raw materials. Therefore, the overall procurement cost of the supply chain can decrease with the attainment of higher amounts of returns."

The conventional view is that reverse logistics imposes costs, slows productivity growth and hinders competitiveness [15]. Reverse logistics and their associated activities result in additional costs in the supply chain when compared to forward logistics regardless of the additional potential associated revenue. The forward chain involves traditional conditions: purchasing from suppliers, producing products, and distribution to end customers. On the other hand, reverse logistics is anything that goes the opposite way of the traditional forward supply chain in the form of returns [6].

The biggest planning problem in remanufacturing and reselling is the uncertain number of collected items from the customer [39]. It is necessary to obtain as much accurate and well-timed information on status, location and condition of products as possible in order to reduce these uncertainties. Furthermore, effective performance management is an important aspect of the reverse logistics initiative in corporations. Organizations are dealing with many uncertainties when facing their market, characterized with a high rate of return due to the expansion of portfolios and shorter life cycles of products, which generates a decisive impact on the strategies of companies [44].

The authors will analyze challenges in reverse logistics as well as technologies that can facilitate information management in reverse logistics. The goal of the paper is to analyze how information management in reverse logistics can be improved, taking into consideration new technologies that are being applied in reverse logistics. The research problem stems from increased costs and insufficient prediction accuracy of reverse logistics operations. This paper presents a review of research papers dealing with this topic. The research results contribute to a better understanding of information management in reverse logistics. 


\section{Theoretical background}

According to Badenhorst \& Nel [5], "some authors define reverse logistics as a set of logistics management tasks or activities, while most of them define it as a process. Secondly, some definitions contain the inputs in reverse logistics, which, most authors agree, include discarded products, used products, products or parts previously shipped, and hazardous and non-hazardous waste. Others look at reverse logistics as a broader concept that includes the entire reverse flow of information, raw materials, inventories and goods through the supply chain".

According to [8], reverse logistics deals with the process of product return from the customer to the manufacturer. Besides, reverse logistics may be also defined as "The process of planning, implementing, and controlling the efficient, cost effective flow of raw materials, in-process inventory, finished goods and related information from the point of consumption to the point of origin for the purpose of recapturing value or proper disposal" [13]. Reverse logistics may also be defined as "all efficient processes for planning, implementing and controlling the flow of raw materials, manufacturing assets, finished products and information relating to this flow, both upstream and downstream, in order to satisfy the end customer / consumer" [18].

Sanchez et al. claim that "studies have focused on describing and analyzing reverse logistics system planning, reverse channel activities and problems that firms encounter in the reverse logistics process [34]. Another line of research examines the ways different elements in the reverse logistics process interact and share information; development of and relationships among members of the supply chain; collaborative production models for planning returns; governance policies; warehousing and environmental sustainability (green reverse logistics) among others."

Figure 1 shows the main processes in forward supply chain and in reverse logistics.

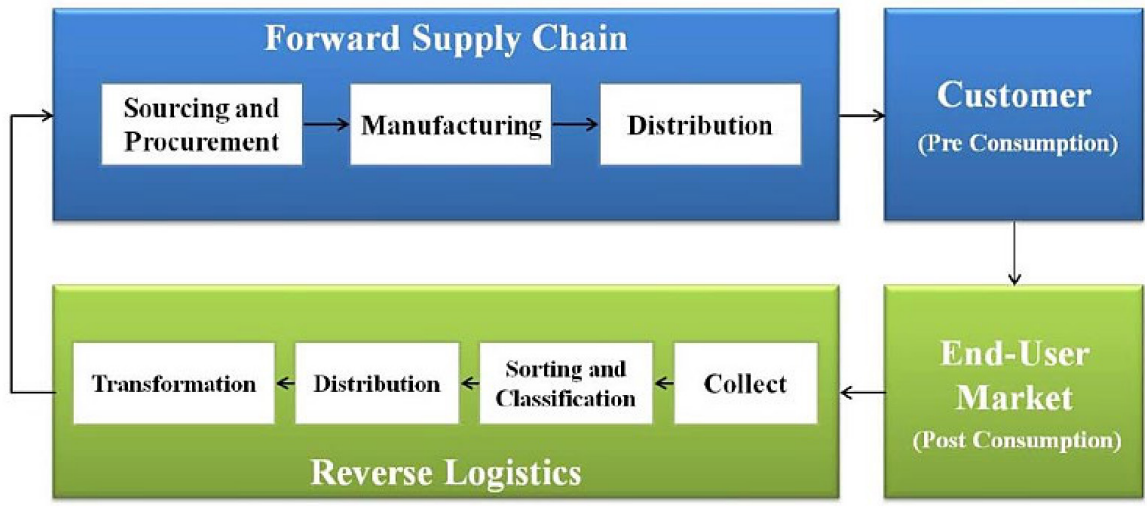

Figure 1: Forward Supply Chain and Reverse Logistics

Source: [27] 
The activities in reverse logistics can be summed up into the collection of the returned product, the evaluation of the product, the sorting and disposal of the products, remanufacturing the product, the act of moving the product and to resale the product in the second-hand market [19].

In addition to the traditional definitions, reverse logistics is often used to describe the efforts to reduce the overall environmental impact of logistics. The terminology is closely related to the term green shipping. Green shipping and reverse logistics can overlap in certain areas, but cannot be used interchangeably [31]. While reverse logistics deals with product returns and the secondary market, green shipping focuses on reducing air emissions and the overall environmental impact. Both terms overlap in recycling, reusing and remanufacturing of products and materials [31].

Disruptive technologies may play an important role in reverse logistics. According to [40], "Disruptive innovations are initially characterized by significant limitations compared with existing technologies but have the potential for dramatic improvements in efficiency, cost reduction or other highly significant benefits".

According to [24], Big Data, Blockchain, and Artificial Intelligence (AI) are identified as some of the most promising and potentially disruptive digital technologies globally. According to [30], disruptive technologies are Big Data, the Internet of Things (IoT), and Cloud Computing, as well as Machine Learning (ML). After the preliminary literature review, the authors have decided to focus on the following disruptive technologies: Blockchain, Internet of Things, Cloud computing and Artificial intelligence.

Blockchain consists of two terms: the "block" and the "chain". "Block" represents transactions, while "chain" links these transactions into one chain. Block is the basic blockchain unit. Each block contains a list of transactions and links to the previous block in the chain. The principle of blockchain technology is accomplished through a decentralized peer-to-peer network. The peer-to-peer network is defined as a data sharing network between many working units [7]. Blockchain is designed as a basis for applications that involve transaction and interactions. These can include smart contracts (smart contracts are automatically carried out when a specific condition is met, for instance regarding the conditions of goods or environmental conditions) or other smart applications that support specific Internet of Things processes. In this way, blockchain technology can improve not just compliance in the IoT but also IoT features and cost-efficiency [16].

Internet of Things is considered one of the disruptive technologies and has attracted lots of research attention in the recent past [41], [42], [35]. The IoT can be considered as "the novel generation of Wireless Sensor Networks (WSN) and it represents a network composed of heterogeneous sensing devices, connected together over the Internet, to acquire information and forward it to a center of collect (base station)" [10].

Artificial intelligence (AI), also known as machine intelligence, is a branch of computer science that aims to imbue software with the ability to analyse its environment using either predetermined rules and search algorithms, or pattern recognizing machine 
learning models, and then make decisions based on those analyses [3]. Cloud computing may be defined as the delivery of computing services - including servers, storage, databases, networking, software, analytics, and intelligence - over the Internet ("the cloud") to offer faster innovation, flexible resources, and economies of scale [25].

\section{Methodology}

Based on the literature review, authors have analyzed the challenges in reverse logistics and singled out and analyzed the following disruptive technologies in transport: Blockchain, Internet of Things and technologies that enable Predictive analytics (Cloud computing and Artificial intelligence).

Blockchain technology is a potential solution to numerous problems such as: insufficient availability of cargo monitoring and lack of transparency (resulting from poor data handling), relying on paperwork in $21^{\text {st }}$ century [20]. Internet of Things, as another innovation, facilitates planning and management of business processes by implementation of modern information technologies [21].

Artificial Intelligence is identified as one of the most promising and potentially disruptive digital technologies globally [24]. Furthermore, Cloud computing is empowering supply chain managers with new-age solutions which are aiding in performance management [11].

The authors started with the inclusion criteria by using a combination of keywords connected with logical operators - "Reverse logistics challenges" and "Reverse logistics technologies" and alternative keywords "Reverse logistics Blockchain" and "Reverse logistics Internet of Things", "Reverse logistics and Predictive analytics" (title, abstract and keywords). Web of Science, Google Scholar, ResearchGate and SpringerLink's databases were used for this purpose. The search mostly included journal articles and conference papers. To ensure that possible useful findings from various fields were not excluded, the authors did not limit the queries to a specific field or index.

\section{Challenges in reverse logistics}

According to [32], successful implementation of reverse logistics networks requires many decisions relating to different hierarchical levels: strategic, tactical, and operational. In practice, numerous reverse logistics networks can be observed that depend on the nature of the returned product (end-of-life, etc.), the recovery process (remanufacturing, reuse, recycling), or the forward channel structure (centralized, decentralized). In this respect, it is actually difficult to find a supply chain where reverse logistics is not present at least to some degree.

The challenges in the reverse logistics may be divided into: customers' negative perception of returning the products ranked as the biggest challenge, high cost associated with reverse logistics, uncertainties relating to product returns, lack of collaboration 
with supply chain partners in reverse logistics, and lack of top management awareness of the importance of reverse logistics [2]. In this paper, the focus will be on the following challenges: high cost associated with reverse logistics, lack of collaboration between supply chain partners in reverse logistics, and insufficient prediction accuracy in the reverse logistics chain.

Most organizations' supply-chain managements, and enterprise resource managements, focus only on forward logistics. The result is poor data visibility, decisions support for returns and disposition policies which leads to low customer satisfaction regarding the reverse channel [19]. The lack of information is a reoccurring problem through the whole process of Reverse logistics [19].

According to [22], lack of information and technological systems represent of one the challenges in reverse logistics. Reliable information is necessary for individual tracking and tracing of the returns so that the returned goods can be distributed according to their condition. Furthermore, the data collection helps to understand the reason for the customer's return and reveal trends as well as root causes.

Efficient information technologies are supportive for individually tracking and tracing the returns of the product, linking with the previous sales. Furthermore, the success of any large business or enterprise in achieving its goals depends on the ability of IT systems to effectively communicate with each other. However, IT systems from different vendors or suppliers often use different hardware and/or software platforms and services, thus creating the need for systems integration [12].

Reverse logistics requires specialized operations and information technology since it is very time-sensitive and includes a variety of tasks like inspection of returned goods, crediting customer accounts and resale of returned goods [19]. Adequate information infrastructure and appropriate software are needed for this purpose [39].

Another vital aspect of reverse logistics information systems is the extended timetracking period. The information system needs to overlook the whole product life cycle, which can include years. These long periods are creating complex problems, on how the continuous data record can happen.

The information about the product attributes is critical for the reuse and recycling of the product [14]. To cope with these massive amounts of data, managers must have the right decision support from an IT system. The lack of an adequate information infrastructure can potentially slow down the efficiency of reverse logistics and lead to dissatisfied customers [19]. Furthermore, products conditions and other characteristics can vary (for example, the broad range of possible locations and different states of arriving products) [14]. This can lead to vast amounts of costs for recovery of the product and for the re-evaluation of the product. The information system should help to organize the information [19]. 


\section{The impact of disruptive technologies on information management in reverse logistics}

Companies across the supply chain have started to invest in new and disruptive technologies in order to derive more benefits and to save costs. The following technologies, used to enhance reverse logistics processes and information management, have been analyzed.

\section{Blockchain}

Blockchain technology is a digital and distributed ledger which enables decentralization, real-time peer-to-peer operation, transparency etc. It is based on a method by which previously unknown parties can jointly generate and maintain almost any database on a fully distributed basis [20]. Blockchain has also been adopted as a technology for logistics management using RFID chips to encompass the whole logistics channel from the manufacturer to the reseller, so that there is seamless exchange of goods and information, high security, transparency and traceability amongst all parties. The customer also has an opportunity to view the history of the purchased items and are able to track the items along the supply chain. This technology is believed to be capable of altering reverse logistics management [36].

By speeding turnaround, increasing efficiency and improving partner connectivity via digital platforms, Blockchain will lower barriers to entry across the supply chain driving innovation and dynamism in the industry and enabling reverse logistics without any extra cost [12].

ShipChain, as a Blockchain solution, is a platform for the global monitoring of goods. With the support of the ShipChain platform, there will be a possibility of monitoring cargo and status points globally, i.e. on all geographic points. Each point will be encrypted and available for interpreting and only involved stakeholders will see all the cargo data. Carriers will have more visibility through their supply chain and will communicate easily. Information on loads, geographic points, and basic compliance information will be recorded and publicly validated within the "sidechain" [33]. When distributed ledger technology joins supply chain management, companies can make reverse logistics more efficient, better track product history, generate trustworthy freight invoices, etc. [9]. Data held in the blockchain can confirm that returned products are genuine, identify the retailer that sold them, and then track items as they are refurbished for resale, liquidated, or sent for disposal [9]. Online orders are subject to a 30-percent return rate, which is a pretty significant percentage. The introduction of blockchain in reverse logistics can help reduce instances of over and under-ordering, track and verify returns against original transactions, and minimize costs [38]. 


\section{Internet of Things}

Internet of things (IoT) gives a clear coverage of visibility when storing and sharing information between departments which creates allowances for them to implement tracking, planning, and the control of all processes [37], [45]. Some enabling communications of IoT is done via radio-frequency identification (RFID) technology and this is aided by the Wireless Sensor Network (WSN) technology. This technology can control all devices through a centralized network or cloud system in co-ordination with RFID, global positioning system (GPS) and sensors that receive information from the Internet of Things to initiate certain functions [37]. Logistics management will become smarter, more advanced and efficient throughout all of its working functions [37].

The Smart Reverse Supply Chain (SRSC) is a concept in green manufacturing management engineering that enables intelligent combination of various systems (e.g. recycling, supply chain management systems, etc.) in a business. As RFID electronic tags and sensors are becoming increasingly widespread, it utilizes advanced information system to enable real-time management of product information during its entire lifecycle. The following Figure shows the integration of SRSC [45].
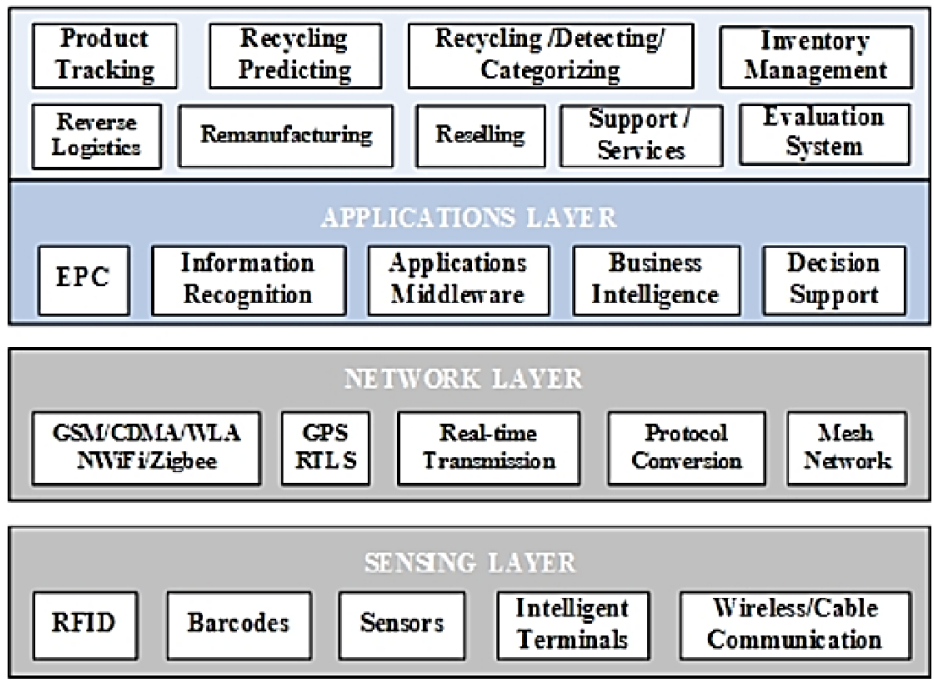

Figure 2: The integration of Smart Reverse Supply Chain Source: [45]

The integration of SRSC consists of three layers. Based on sensing and information network technology of IoT, it integrates product tracking systems, predicting systems, recycling/detecting/categorizing systems, reverse logistic and inventory management systems, re-manufacturing execution systems, re-manufacturing sales system and 
evaluation system etc. [45]. This integration is not only able to realize integrated information management within a business, but also product recycling and remanufacturing [45].

\section{Predictive analytics}

Predictive analytics is the use of advanced analytic techniques that leverage historical data to uncover real-time insights and to predict future events [17]. Authors have focused on Cloud computing and Artificial intelligence in the context of Predictive analytics. Many businesses rely on Artificial intelligence and Predictive analytics to improve their service, streamline operations and predict customer churn so it can be stopped before it occurs [4]. The use of analytics can be applied to gain an insight of what is likely to happen, what needs to happen to avoid low outcomes, and why certain events may lead to a given outcome.

According to [1], at the operational level, the artificial intelligence can provide: improved predictive management of assets, maximizing its use and avoiding interruptions in supply chains due to the shutdown of machines and equipment; improved monitoring and visibility of the operations carried out in the supply chain, allowing decision making and optimizations much more dynamic.

Cloud computing technology has enabled a new generation of analytics which can be applied to reverse logistics [43]. Cloud analytics is a service model where one or more components of analytics are implemented in the cloud. The cloud model allows organizations to scale analytics capabilities as their company grows. It also processes large volumes of Big Data, as it is ingested into a data warehouse [26].

Although analytics are a revolutionary way to improve warehouse operations, such improvements may not be possible or may be severely limited when analytics in reverse logistics are ignored. Warehouse Managers should begin the process of implementing systems to leverage the power of analytics in reverse logistics [43].

According to Association of Supply Chain Management, companies that have incorporated predictive analytics into their reverse-logistics operations have seen an improvement in service levels with fewer phone calls and reported issues. They've also realized freight savings between $5 \%$ and $10 \%$ by reducing last-minute load requests [4].

\section{Conclusion}

Reverse logistics is part of the overall logistics which deals with the management of goods that the customer returns to the manufacturer. After increasing demand for returnable products, many challenges occurred. The challenges in reverse logistics can be divided into the following: the customers' negative perception of the returning products, high costs associated with reverse logistics, uncertainties regarding product returns and lack of cooperation between supply chain partners in reverse logistics. 
This paper has focused on the following challenges: high costs associated with reverse logistics, lack of cooperation between supply chain partners in reverse logistics and insufficient predictive accuracy in the reverse logistics chain.

Most organizations focus only on forward logistics, resulting in poor data visibility. The lack of information and technological systems in reverse logistics is one of the challenges. Reliable information is necessary for the individual tracking and tracing of returns so that the returned goods can be distributed according to their condition. In addition, data collection helps to understand the reason for the customer's return and to uncover trends and causes.

Companies across the supply chain have started to recognize benefits of new and disruptive technologies in order to derive more benefit and to reduce costs. In this paper, authors have focused on the following disruptive technologies: Blockchain, Internet of Things and two technologies that enable Predictive analytics: Cloud computing and Artificial intelligence.

Blockchain can increase reverse logistics efficiency, better track product history, create trustworthy freight invoices, and more. Data stored in the Blockchain can confirm that returned products are genuine, identify the retailer who sold them, and then track items as they are prepared for resale, liquidated or sent for disposal. The introduction of Blockchain in reverse logistics can help reduce over-ordering and under-ordering, track and verify returns against original transactions, and minimize costs.

Internet of Things provides a clear visibility when storing and sharing information between departments and facilitates tracking, planning, and the control of all processes. Furthermore, Internet of Things can control all devices through a centralized network or a cloud system in coordination with RFID, a global positioning system and sensors that obtain information from the IoT.

Companies can also use Artificial intelligence and Cloud computing which enable Predictive analytics, in order to improve their services, streamline operations and predict customer churn. At the operational level, Artificial intelligence can provide: improved predictive asset management, maximizing asset utilization and avoiding supply chain disruptions due to machine and equipment shutdowns. Furthermore, Artificial intelligence can provide improved monitoring and visibility of operations performed in the supply chain, making decision-making and optimization much more dynamic. Cloud computing enables a new generation of analytics that can be applied to reverse logistics and process large volumes of Big Data.

This research is based on the literature review and considers three selected disruptive innovations (which is also the main limitation of the research), and as such offers the initial overview of the importance of disruptive technologies in reverse logistics. Future research will include other disruptive technologies in order to obtain a broader insight of disruptive technologies impacts on information management in reverse logistics. 


\section{References}

1. Aguezzoul, A. and Pires, S. (2019) Use of Artificial Intelligence in Supply Chain Management Practices and 3PL Selection. Available at: http://www.iiisci.org/journal/CV\$/sci/pdfs/CK424QA19. pdf (Accessed: 18 June 2020).

2. Amole, B. B., Adebiyi, S. O. and Arogundade, K. K. (2018) 'Reverse logistics and management of waste products: the Nigerian Manufacturing Firms Experience', Review of Innovation and Competitiveness, 4(3), pp. 57-74.

3. Artificial Intelligence (AI) (2020). Available at: https://www.techopedia.com/definition/190/ artificial-intelligence-ai (Accessed: 14 June 2020).

4. ASCM (2020) Use Artificial Intelligence to Improve Reverse Logistics. Available at: https:// www.ascm.org/ascm-insights/use-artificial-intelligence-to-improve-reverse-logistics/ (Accessed: 8 June 2020).

5. Badenhorst, A. and Nel, J. D. (2012) Identifying potential solutions for specific reverse logistics problems. Available at: https://www.researchgate.net/publication/307846412 Identifying potential_solutions_for_specific_reverse_logistics_problems (Accessed: 6 April 2020).

6. Breese, J. L., Park, S.-J. and Vaidyanathan, G. (2019) 'Blockchain Technology Adoption in Supply Change Management: Two Theoretical Perspectives', Issues in Information Systems, 20(2), pp. $140-150$.

7. Centar informacijske sigurnosti (2009) Peer-to-peer mreže. Available at: https://www.cis.hr/www. edicija/Peer-to-peermree.html (Accessed: 29 April 2019).

8. Degbotse, A. et al. (2017) 'Predictive analytics in reverse supply chain management commodity life expectancy for quality engineering', in 2017 IEEE 19th Electronics Packaging Technology Conference (EPTC), pp. 1-7. doi: 10.1109/EPTC.2017.8277546.

9. Douglas, M. (2020) Blockchain, Meet Supply Chain. Available at: https://www.inboundlogistics. $\mathrm{com} / \mathrm{cms} /$ article/blockchain-meet-supply-chain/ (Accessed: 9 June 2020).

10. Duvallet, C., Sadeg, B. and Belfkih, A. (2017) The Internet of Things for Smart Ports Application To the Port of Le Havre. Available at: https://www.redhat.com/en/resources/smart- (Accessed: 14 June 2020).

11. E-Zest (2020) Cloud Computing Solutions for Supply Chain Management. Available at: https:// www.e-zest.com/cloud-computing-solutions-for-supply-chain-management (Accessed: 13 June 2020).

12. Farouk, M. and Darwish, S. M. (2020) 'Reverse Logistics Solution in e-Supply Chain Management by BlockchainTechnology', Egyptian Computer Science Journal, 44(1), pp. 22-34.

13. Govindan, K., Soleimani, H. and Kannan, D. (2015) 'Reverse logistics and closed-loop supply chain: A comprehensive review to explore the future', European Journal of Operational Research, 240(3), pp. 603-626.

14. Gu, Y. and Liu, Q. (2013) 'Research on the application of the internet of things in Reverse logistics information management', Journal of Industrial Engineering and Management, 6(4), pp. 963-973.

15. Huang, Y.-C. and Yang, M.-L. (2014) 'Reverse logistics innovation, institutional pressures and performance', Management Research Review, 37(7), pp. 615-641.

16. i-SCOOP (2018) Blockchain and the Internet of Things: the IoT blockchain opportunity and challenge. Available at: https://www.i-scoop.eu/blockchain-distributed-ledger-technology/ blockchain-iot/ (Accessed: 15 July 2019).

17. IBM (2020) Predictive analytics. Available at: https://www.ibm.com/analytics/predictive-analytics (Accessed: 12 June 2020).

18. Inter-logistics (2020) Understand the returns management / reverse logistics process. Available at: https://www.inter-logistic.eu/en/e-commerce-logistics/returns-management-reverse-logistics. html (Accessed: 4 June 2020).

19. Jayaramana, V., Ross, A. D. and Agarwal, A. (2008) 'Role of information technology and collaboration in reverse logistics supply chains', International Journal of Logistics: Research and Applications, 11(6), pp. 409-425.

20. Jović, M., Filipović, M., et al. (2019) 'A review of blockchain technology implementation in shipping industry', Pomorstvo, 33(2), pp. 140-148. Available at: https://hrcak.srce.hr/229259 . 
21. Jović, M., Tijan, E., et al. (2019) ‘An Overview Of Security Challenges Of Seaport IoT Systems', in 42nd International Convention on Information and Communication Technology, Electronics and Microelectronics (MIPRO). Opatija, Croatia: MIPRO Proceedings Digital Economy/Digital Society 2019. Available at: https://bib.irb.hr/prikazi-rad?rad=986080.

22. Kaynak, R., Koçoğlu, İ. and Akgün, A. E. (2014) 'The Role of Reverse Logistics in the Concept of Logistics Centers', Procedia - Social and Behavioral Sciences, 109, pp. 438 - 442.

23. Larsen, S. (2017) How the reverse supply chain impacts the financial performance of original equipment manufacturers. Available at: https://backend.orbit.dtu.dk/ws/files/131830981/PhD thesis_Summary_Samuel_Br_ning_Larsen.pdf (Accessed: 8 June 2020).

24. Linkov, I. et al. (2018) 'Governance strategies for a sustainable digital world', Sustainability (Switzerland), 10(2), pp. 1-8. doi: 10.3390/su10020440.

25. Microsoft Azure (2020) What is cloud computing? Available at: https://azure.microsoft.com/en-us/ overview/what-is-cloud-computing/ (Accessed: 14 June 2020).

26. MicroStrategy (2020) Cloud Analytics: Everything You Need to Know. Available at: https://www. microstrategy.com/us/resources/introductory-guides/cloud-analytics-everything-you-need-to-know (Accessed: 13 June 2020).

27. Nicolau, J. J. N. (2016) Impact of RFID information-sharing coordinationover a supply chain with reverse logistics. Available at: https://docs.lib.purdue.edu/cgi/viewcontent. cgi?article $=2195 \&$ context $=$ open_access_dissertations (Accessed: 4 June 2020).

28. Reddy, D. (2019) A study on Reverse Logistics. Available at: http://www.diva-portal.org/smash/ get/diva2:396019/fulltext01.pdf (Accessed: 8 June 2020).

29. Rehman, S. A., Zhang, Y. and Khan, S. S. (2017) 'Reverse Logistics and Challenges: Supply Chain Management of Automobile Industry', Advances in Applied Sciences, 2(5), pp. 80-86.

30. Rodríguez-Rodríguez, I., Zamora-Izquierdo, M. Á. and Rodríguez, J. V. (2018) 'Towards an ICTbased platform for type 1 diabetes mellitus management', MDPI Applied Sciences (Switzerland), 8(4), pp. 1-15. doi: 10.3390/app8040511.

31. Rogers, D. and Lembke, R. S. (2001) 'An Examination of Reverse Logistics Practices', Journal Of Business Logistics, 22(2), pp. 129-148.

32. Rubio, S. and Jiménez-Parra, B. (2014) 'Reverse Logistics: Overview and Challenges for Supply Chain Management', International Journal of Engineering Business Management, 6(12), pp. 1-7.

33. S\&amp;R-Shipchain-Outline Content Breakdown (2017). Available at: https://static1.squarespace. com/static/5b58858a710699d85d651e42/t/5b65b09c1ae6cf3410eebde7/1533391031469/S\%26R\%2BShipchain-\%2BOutline.pdf (Accessed: 26 April 2019).

34. Sanchez, E. G., Guerrero-Villegas, J. and Aguilera-Caracuel, J. (2019) 'How Do Technological Skills Improve Reverse Logistics? The Moderating Role of Top Management Support in Information Technology Use and Innovativeness', MDPI Sustainability, 11(1), p. 58. doi: https:// doi.org/10.3390/su11010058.

35. Sánchez, P. et al. (2018) 'A teleo-reactive node for implementing internet of things systems', MDPI Sensors (Switzerland), 18(4). doi: 10.3390/s18041059.

36. Shah, S., Dikgang, G. and Menon, S. (2019) 'The Global Perception of Industry 4.0 For Reverse Logistics', International Journal of Economics and Management System, 4(2019), pp. 103-107.

37. Shah, S., Rutherford, R. and Menon, S. (2020) 'Emerging Technologies of IoT Usage in Global Logistics', in 2020 International Conference on Computation, Automation and Knowledge Management (ICCAKM). Dubai, United Arab Emirates, pp. 251-257. doi: 10.1109/ ICCAKM46823.2020.9051530.

38. ShipChain (2018) Mitigating Logistics Risk Through Blockchain. Available at: https://blog. shipchain.io/mitigating-logistics-risk-through-blockchain/ (Accessed: 9 June 2020).

39. Tao, J. (2010) 'Reverse Logistics Information System of E-waste Based on Internet', in 2010 International Conference on Challenges in Environmental Science and Computer Engineering. Wuhan, pp. 447-450.

40. Ullah, F., Sepasgozar, S. M. E. and Wang, C. (2018) 'A systematic review of smart real estate technology: Drivers of, and barriers to, the use of digital disruptive technologies and online platforms', Sustainability (Switzerland), 10(9). doi: 10.3390/su10093142.

41. Ullah, I. et al. (2019) 'Cloud Based IoT Network Virtualization for Supporting Dynamic Connectivity among Connected Devices', MDPI Electronics, 8(7), p. 742. doi: 10.3390/ electronics8070742. 
42. Ullah, I., Ahmad, R. and Kim, D. H. (2018) 'A prediction mechanism of energy consumption in residential buildings using hidden markov model', MDPI Energies, 11(2), pp. 1-20. doi: 10.3390/ en11020358.

43. Veridian (2018) Understanding the Role of Analytics in Reverse Logistics. Available at: https:// veridian.info/analytics-in-reverse-logistics/ (Accessed: 8 June 2020).

44. Voigt, D. et al. (2019) 'Performance Evaluation of Reverse Logistics: Opportunities for Future Research', MDPI Sustainability, 11, p. 5291.

45. Xu, X., Wu, X. and Guo, W. (2011) Applications of IoT to Reverse Supply Chain. Available at: https://ieeexplore.iee.org/stamp/stamp.jsp?tp=\&arnumber=6040568 (Accessed: 8 June 2020).

46. Zampou, E. et al. (2018) 'Big data analytics in e-commerce logistics: Findings from a systematic review and a case study', Proceedings of 7th Transport Research Arena TRA 2018. 
